\title{
PROLONGED NASOTRACHEAL INTUBATION IN INFANTS AND CHILDREN
}

W. G. Markham, M.D., M. J. A. BlackWOod, M.B., CH.B., D.A., F.F.A.R.C.s., AND A. W. CONN, M.D., B.SC.(MED.), F.R.C.P.(C)

REPORTS on the successful use of prolonged nasotracheal intubation in infants and children have come from a number of paediatric centres in recent years. ${ }^{1-5}$ The technique has also been in use at the Hospital for Sick Children in Toronto, and this report outlines our experiences during the period from January 1, 1965 to December 31, 1965. A total of 156 patients were intubated for 24 hours or longer, with 74 long-time survivors. These patients were totally unselected and were treated with this technique regardless of the prognosis. In the patients who died, prolonged intubation was not a major contributing factor.

A classification of the groups of patients treated with prolonged nasotracheal intubation is given in Table I. The duration of intubation according to group is listed in Table II and the number of cases according to duration in Figure 1.

\section{Intubation}

\section{MANAGEMENT}

Route of intubation. For prolonged intubation, the nasal route is preferred. This has the following advantages over oral intubation: $(a)$ more effective fixation can be achieved; $(b)$ oral feeding is possible; $(c)$ excessive salivation is avoided; and $(d)$ obstruction of the tube due to kinking is less likely to occur.

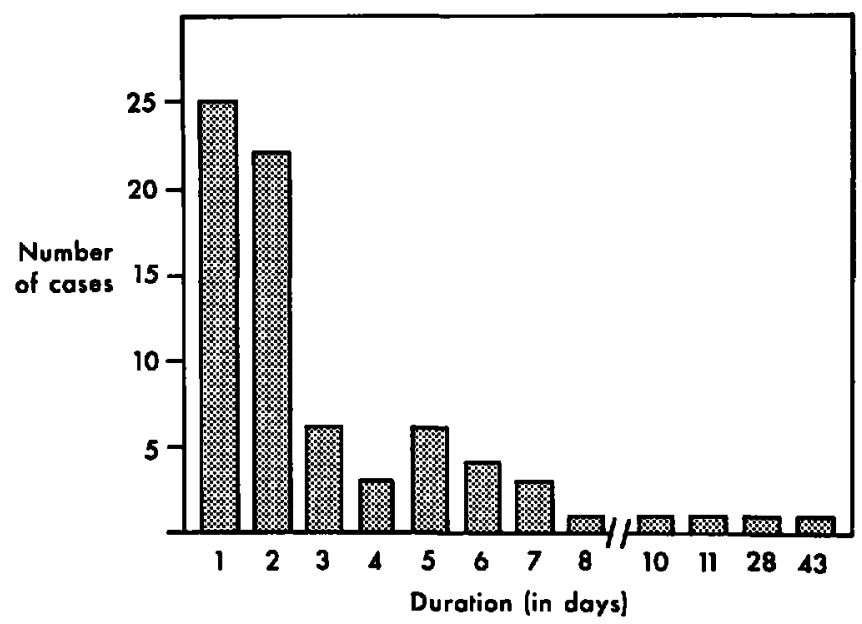

Frgune 1. Duration of intubation in days.

-Department of Anaesthesia, University of Toronto, and the Hospital for Sick Children, Toronto, Ontario. 
TABLE I

Classification of Patients

\begin{tabular}{lcc}
\hline \hline & $\begin{array}{c}\text { Total number } \\
\text { of cases }\end{array}$ & Survived \\
\hline Cardiovascular & 80 & 42 \\
Neurological & 37 & 13 \\
Respiratory & 20 & 15 \\
Miscellaneous & 19 & 4 \\
Total & 156 & 74 \\
\hline
\end{tabular}

TABLE II

DURATION OF INTUBATION

\begin{tabular}{lrrrrr}
\hline \hline & \multicolumn{5}{c}{ Number of cases } \\
\cline { 2 - 6 } Duration (days) & C.V.S. & C.N.S. & Resp. S. & Misc. & Total \\
\hline 1 & 15 & 3 & 5 & 2 & 25 \\
2 & 12 & 3 & 6 & 1 & 22 \\
$3-4$ & 5 & 2 & 1 & 1 & 9 \\
$5-6$ & 6 & 3 & 1 & - & 10 \\
$7-10$ & 2 & 1 & 2 & - & 5 \\
Over 10 & 2 & 1 & - & - & $\mathbf{3}$ \\
Total & 42 & 13 & 15 & 4 & 74 \\
\hline
\end{tabular}

Anaesthesia for intubation. Patients are preoxygenated for a few minutes prior to intubation. As a rule, infants in the recovery room and I.C.U. are intubated either awake or following administration of atropine and a relaxant (usually d-tubocurare). For older children, intubation may be performed: (a) In the recovery

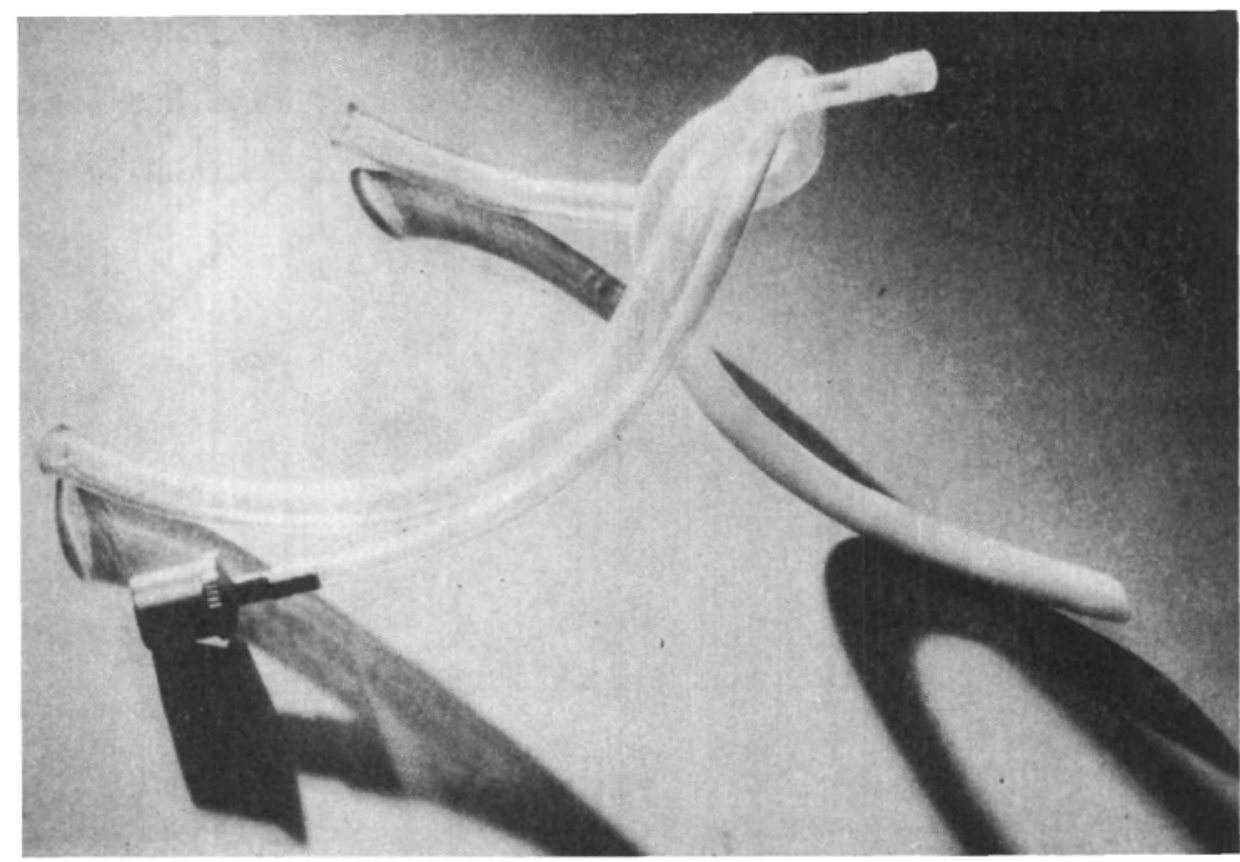

Figure 2. Modified nasotracheal tube. 
room without anaesthesia, either by blind nasal intubation or by using direct laryngoscopy and Magill forceps. (b) In the recovery room during anaesthesia, following the administration of atropine, thiopentone, or halothane, and relaxant (usually succinylcholine or d-tubocurare). Succinylcholine is avoided in seriously ill patients because of its possible adverse effect on the myocardium. (c) In the operating room, after anaesthesia, at the end of the surgical procedure and before the patient recovers.

Diameter of the endotracheal tube. With this technique, selection of a tube of optimal size is of major importance. Too large a tube may result in ischaemic changes in the subglottic mucosa and damage to the vocal cords. Too small a tube may result in ineffective ventilation from a respirator because of the leakage of gas, and possible aspiration of pharyngeal contents into the tracheobronchial tree.

The most important factor governing the choice of tube size is the condition of the upper airway. For patients with upper airway disorders (e.g. laryngotracheobronchitis, epiglottitis), the safest approach is to use the smallest diameter of tube that provides an adequate airway and permits suctioning. ${ }^{3}$ With a normal upper airway, the use of a tube one size smaller than that which completely occludes the airway is preferable.

Types of tubes. For short-term periods (up to three days), the standard Portex polyvinyl nasotracheal tube is used. To avoid dislodgement or kinking of the tube, the patient has to be kept relatively immobile. For longer periods of intubation, a more complex type of tube which is a modification of the Jackson Rees model ${ }^{1}$ may be used (Fig. 2). It consists of a Portex tube which

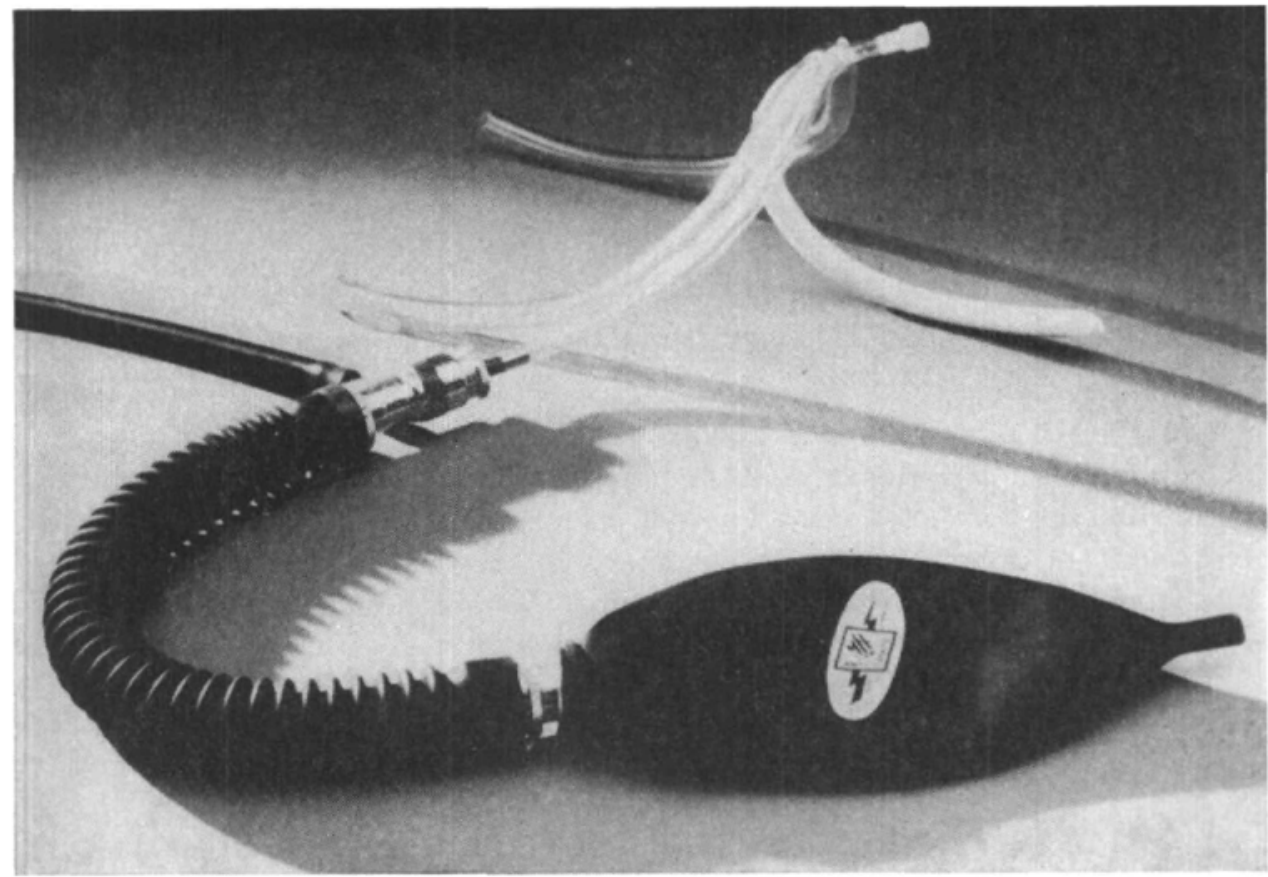

Froure 3. Arrangement for manual inflation. 

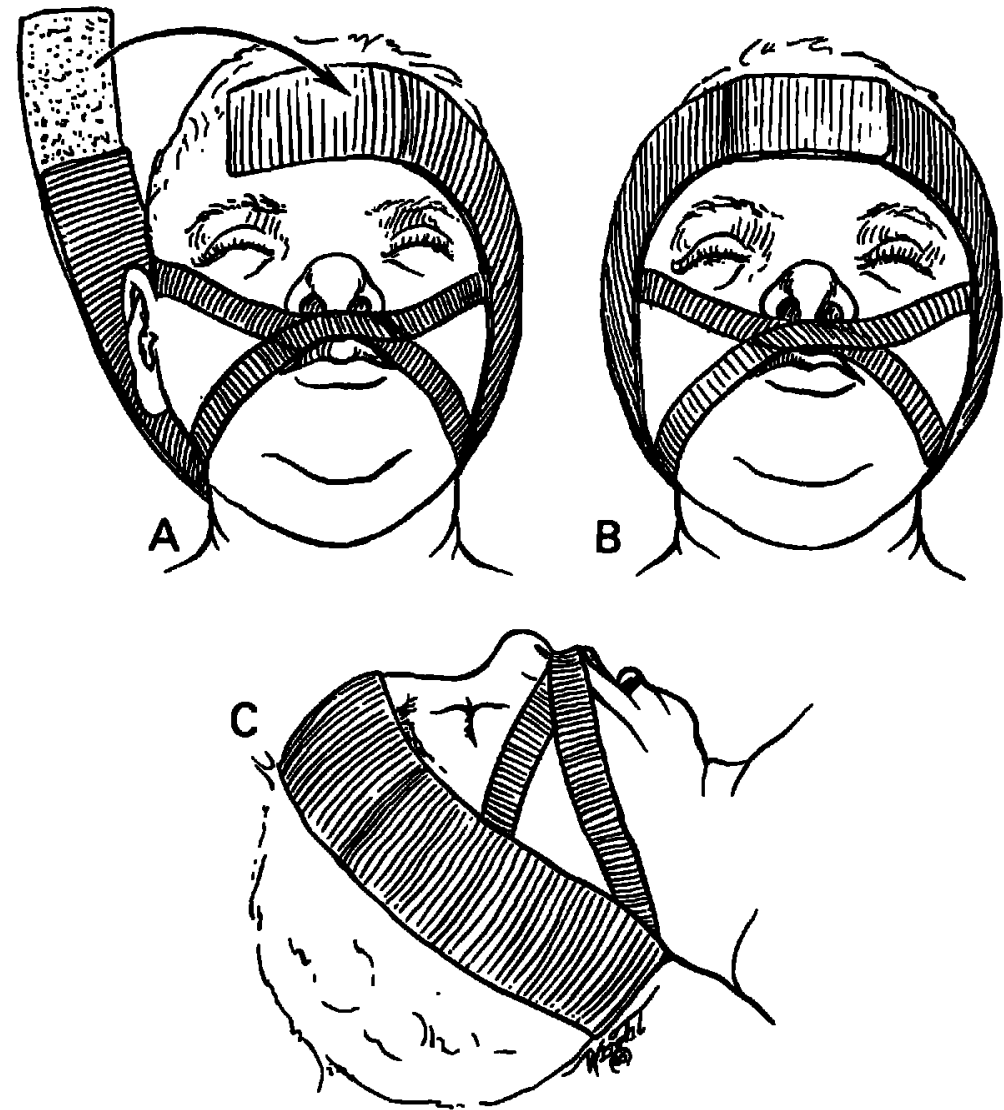

Figure 4. Position of tape on the patient's head.

is permanently attached at its proximal end to a soft flexible plastic tubing, one arm of which attaches to the inspiratory line from the respirator and the other to the expiratory line. A third arm of plastic tubing can be connected to an oxygen supply and bag for manual inflation. In line with the nasotracheal tube is a short length of plastic tubing through which a catheter can be passed for suctioning. Figure 3 illustrates the arrangement for manual inflation.

Method of attachment. The modified nasotracheal tube described above is attached to the patient in the following manner (Fig. 4): (a) two narrow strips of elastoplast tape are placed diagonally across the upper lip extending from above the ear on one side to below the ear on the opposite side, and (b) two strips of $2^{\prime \prime}$ elastoplast, one $6^{\prime \prime}$ longer than the other, are stuck together so that when the tape is wrapped around the head, it is only adherent to the forehead. The patient is then intubated and the tube is sutured both to the tape crossing the upper lip and to the tape encircling the head. This arrangement allows the patient to be positioned and turned without kinking or dislodging the tube. The positioning of the tube in a patient is shown in Figure 5. When the patient is to be inflated manually the clamp on the side arm is removed and placed across both arms of the respirator tubing. The tubes pass posteriorly rather than over the patient's forehead to prevent excessive leverage on the nasotracheal tube and to avoid pressure necrosis to the skin of the forehead. 


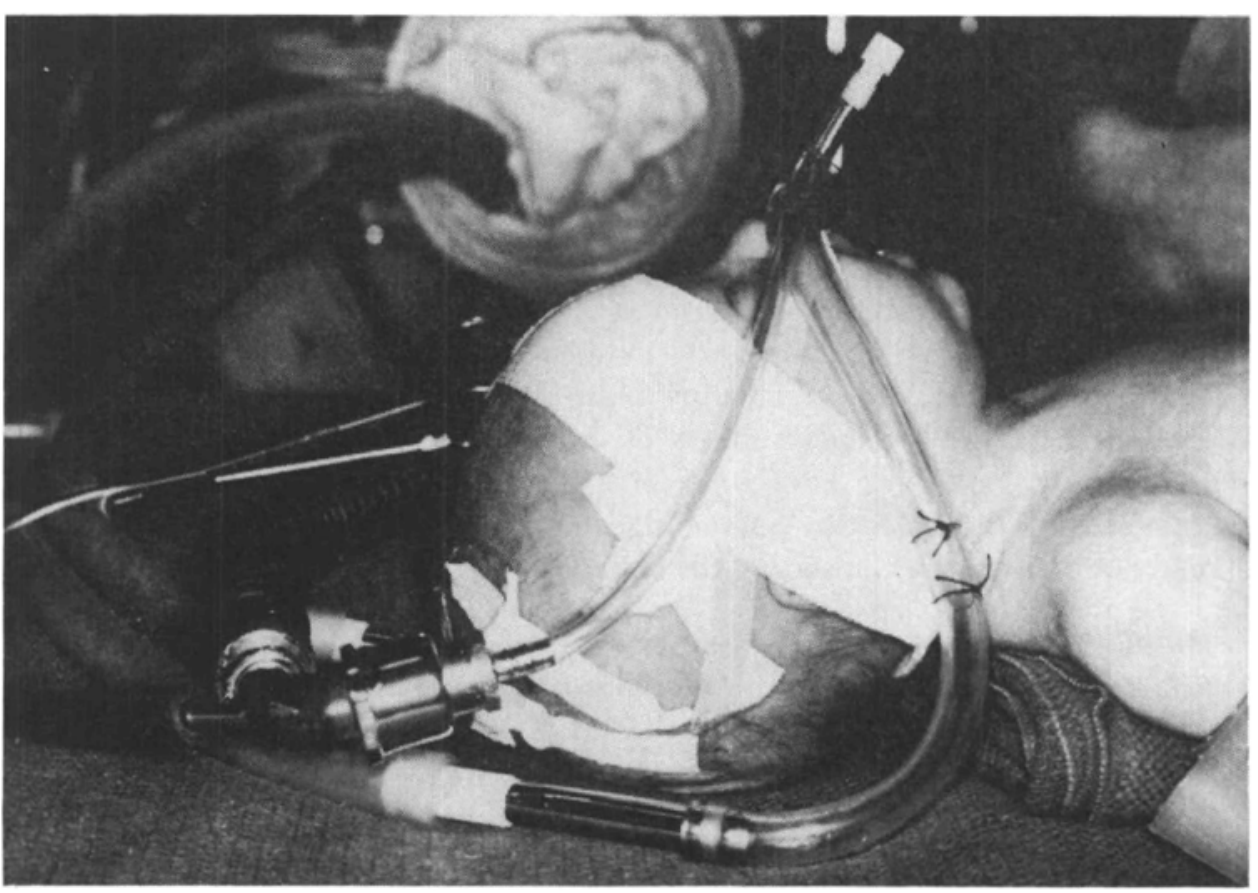

Figune 5, Positioning of the nasotracheal tube.

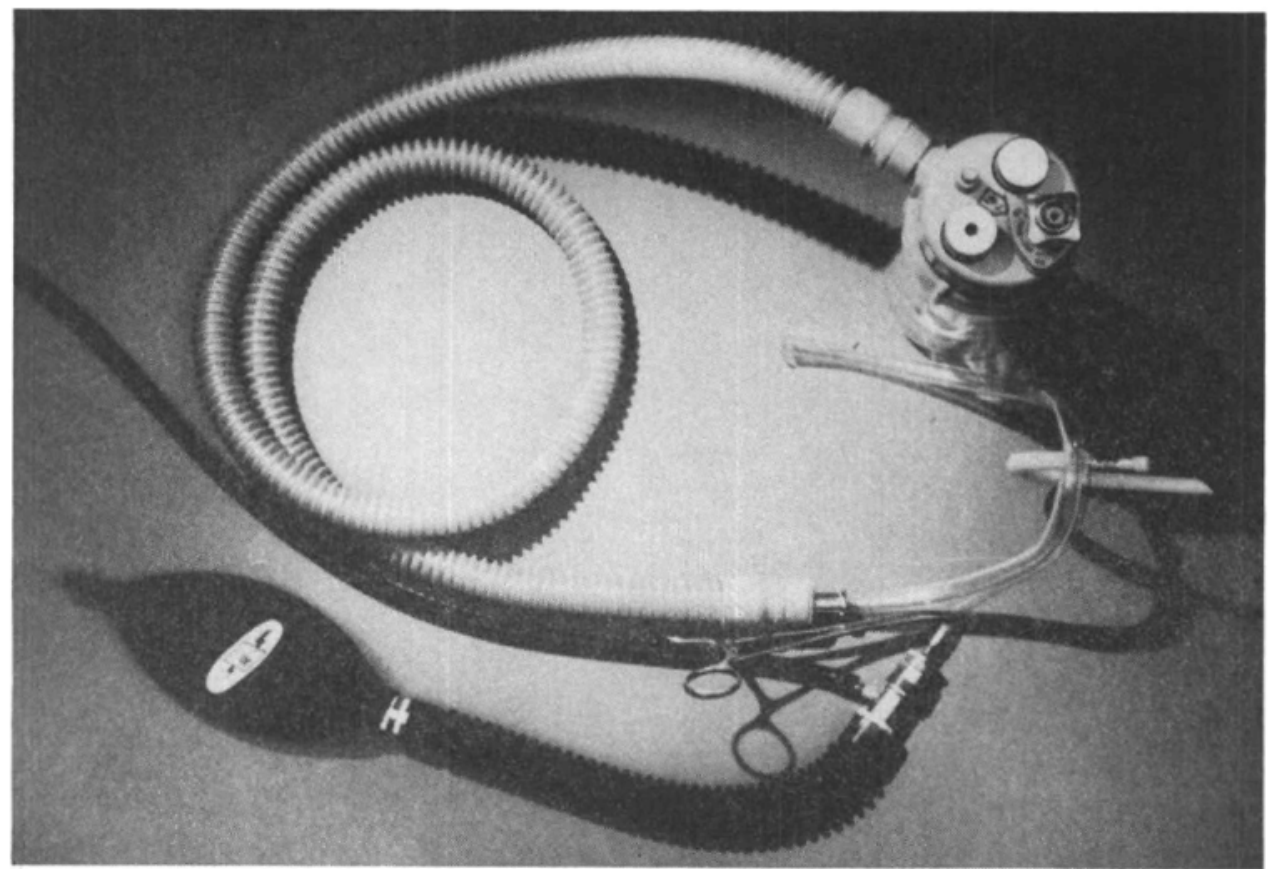

FIGURE 6. Arrangement of tubing during spontaneous ventilation. 
During spontaneous ventilation, the tubing from a Puritan nebulizer is attached to one arm of the tubing, the other arm being left open (Fig. 6). The flow rate must be high enough to prevent rebreathing of expired air.

\section{Suctioning}

Suctioning is carried out only when there is evidence of accumulation of secretions in the tracheobronchial tree, rather than at set time intervals. A meticulous sterile technique is essential if infection is to be avoided. Sterile disposable plastic catheters and disposable plastic gloves are used for this procedure (Fig. 7). Manual inflation with 100 per cent oxygen is carried out before suctioning, between insertions of the catheter, and at the completion of the procedure. A Y-piece is used and negative pressure is applied only during withdrawal of the catheter. Suctioning should be carried out quickly. Force should not be used when inserting the catheter.

\section{Humidification}

Effective humidification of inspired gases is an essenital feature of the management of patients with nasotracheal tubes in place. In addition to humidification provided by the nebulizer of the respirator, tent, or incubator, instillation of saline via the tube into the airway is carried out in all patients. This is performed as a routine procedure every 30 minutes. The minimum average amounts used are $0.5 \mathrm{ml}$. for children under one year of age; $1.0 \mathrm{ml}$. in the one-to-five-year age group, and $2.0 \mathrm{ml}$. for those over five years of age.

Maintenance of the patient's daily fluid requirements is equally important in preventing thickening of tracheobronchial secretions.

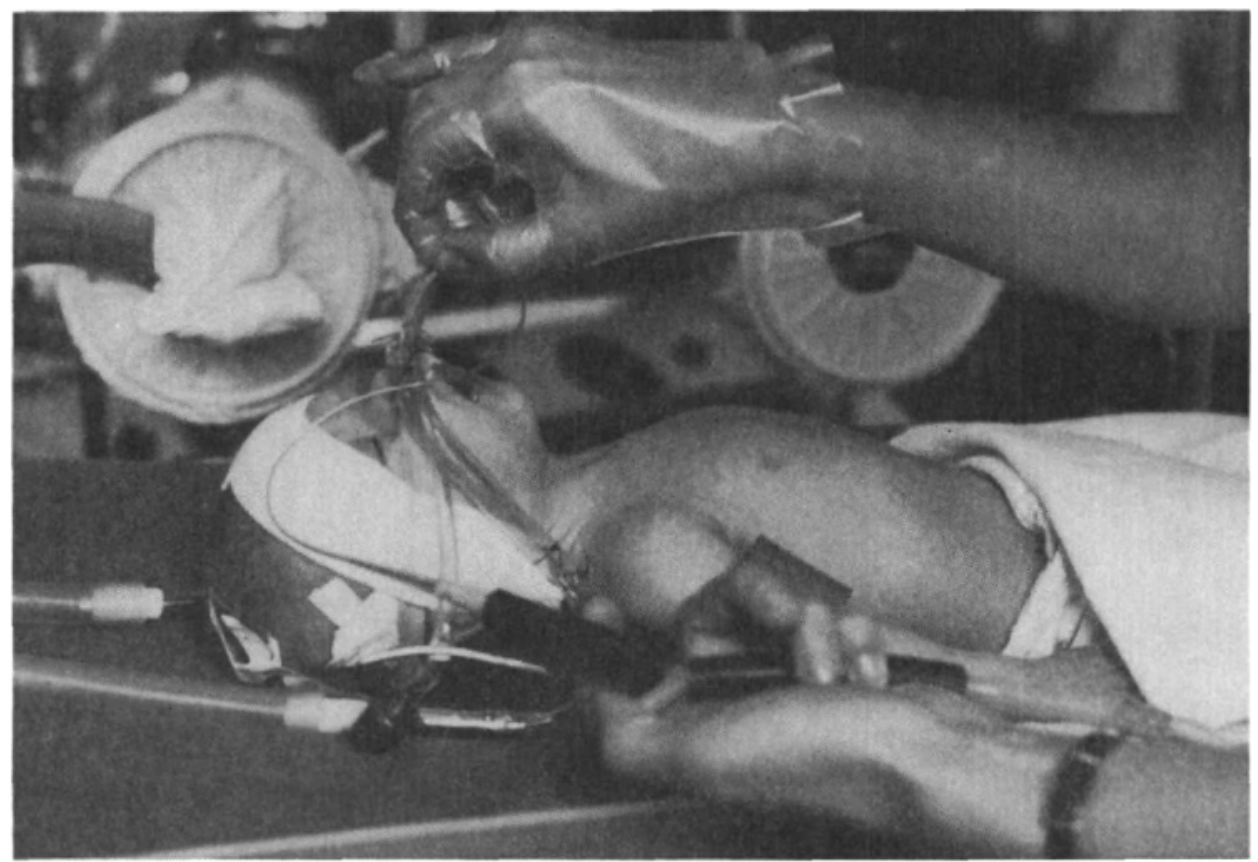

Frcurs 7. Suctioning technique. 


\section{Posturing}

Unless otherwise ordered, patients are turned at thirty-minute intervals. The usual sequence of position change is from the right side to the supine position to the left side and then back to the right side.

\section{Nursing Care}

Expert, experienced nursing care is an obvious requirement for the proper management of these patients. The use of inexperienced nurses will result in an unnecessarily high morbidity and mortality rate.

\section{Laboratory Measurements}

Oxygen tensions and acid-base parameters are measured at frequent intervals using micro $\mathrm{pH}, \mathrm{P}_{\mathrm{CO}_{2}}$, and $\mathrm{P}_{\mathrm{O}_{2}}$ electrodes. In most instances, "arterialized" capillary blood sampling is used. In infants under one year of age, the blood is taken from the heel, but in those over one year, the samples are taken from the ear lobe.

\section{Management Following Extubation}

Steroids are administered for at least 24 hours following extubation to minimize oedema of the tracheal mucosa. Hydrocortisone is given intravenously or intramuscularly one hour prior to extubation. Cortisone acetate is given intramuscularly at the time of extubation and 8 and 16 hours later.

TABLE III

Dosage of Steroids

\begin{tabular}{lcc}
\hline \hline \multicolumn{1}{c}{ Age } & Hydrocortisone (mg.) & Cortisone \\
\hline Under one year & 25 & 25 \\
One to five years & 50 & 50 \\
Over five years & 100 & 100 \\
\hline
\end{tabular}

\section{Posturing}

In infants and small children the supine position is avoided, if possible, for the first few days following extubation to minimize the possibility of aspiration.

\section{Feeding}

For some hours after extubation, reflex closure of the vocal cords may be inefficient and aspiration is prone to occur. To minimize possible pulmonary complications, feeding in infants and small children is changed to sugar solution for the first $\mathbf{2 4}$ hours following removal of the tube.

\section{Hoarseness}

\section{Complications Following Extubation}

Hoarseness is commonly present for the first few days following removal of the tube, but rarely persists for more than a week. 


\section{Airway Obstruction}

In this series, obstruction severe enough to require a tracheotomy occurred in five cases. The principal causes of this complication are (a) subglottic oedema; (b) subglottic web formation; and (c) subglottic cicatricial narrowing.

\section{Subglottic Oedema}

This complication was considered serious enough to require a tracheotomy in two cases. In one patient (K.R.) the tracheotomy tube was subsequently removed ( 9 days later) and there has been no further recurrence of airway obstruction. In the second patient (P.M.) a tracheotomy tube is still in place. A bronchoscopy done a few months after extubation showed narrowing of the glottic opening due to fibrous adhesions but no pathology at the subglottic level. The adhesions were easily separated but, to date, attempts at decannulation have been unsuccessful.

\section{Subglottic Web Formation}

Subglottic webs developed in two patients. Neither required tracheotomy. One of them (D.C.) required tracheal dilatation on six occasions over a three-week period, but none have been necessary for the past eight months.

In the second case (I.K.) only one dilatation was necessary and there has been no further evidence of airway obstruction during the past nine months.

\section{Subglottic Cicatricial Narrowing}

This occurred in three cases. One of them (J.L.) still has an obturator in place. Both of the remaining patients (B.M. and J.C.) required a permanent tracheotomy, One of them (B.M.) died nine months later.

Table IV summarizes the above cases.

TABLE IV

Patients Developing Airway Obstruction Following Extubation

\begin{tabular}{|c|c|c|c|c|}
\hline Patient & Diagnosis & $\begin{array}{l}\text { Duration of } \\
\text { intubation } \\
\text { (days) }\end{array}$ & $\begin{array}{c}\text { Type of } \\
\text { complication }\end{array}$ & Present condition \\
\hline K.R. & Status epilepticus & 1 & Subglottic oedema & Clinically satisfactory \\
\hline P.M. & Status asthmaticus & 3 & Subglottic oedema & $\begin{array}{l}\text { Tracheotomy tube still } \\
\text { in place }\end{array}$ \\
\hline D.C. & Status asthmaticus & 5 & Subglottic web & $\begin{array}{l}\text { Clinically satisfactory } \\
\text { airway }\end{array}$ \\
\hline I.K. & Encephalitis & $\mathbf{3}$ & Subglottic web & $\begin{array}{l}\text { Clinically satisfactory } \\
\text { airway }\end{array}$ \\
\hline J.L. & Status asthmaticus & $\mathbf{5}$ & $\begin{array}{l}\text { Subglottic cicatricial } \\
\text { narrowing }\end{array}$ & Improved, obturator only \\
\hline B.M. & $\begin{array}{l}\text { Ventricular septal } \\
\text { defect and pulmonary } \\
\text { hypertension }\end{array}$ & 43 & $\begin{array}{l}\text { Subglottic cicatricial } \\
\text { narrowing }\end{array}$ & $\begin{array}{l}\text { Died-would have } \\
\text { required a permanent } \\
\text { tracheotomy }\end{array}$ \\
\hline J.C. & Coarctation of aorta & 5 & $\begin{array}{l}\text { Subglottic cicatricial } \\
\text { narrowing }\end{array}$ & Permanent tracheotomy \\
\hline
\end{tabular}


Pulmonary infection is a potential problem with endotracheal intubation. With the use of a sterile suctioning technique, efficient humidification, and chest physiotherapy, along with the proper cleaning of the equipment used in the care of these patients, it is possible to minimize the incidence of the complication. Antibiotics are not given prophylactically in these patients.

\section{Discussion}

It is now apparent that endotracheal tubes can be safely left in position for longer periods than had previously been acceptable. A surprising feature of this technique has been the tolerance patients have shown to having an endotracheal tube in place. After an explanation to older patients of the need for a tube in the airway, combined with sedation, the whole procedure is accepted remarkably well.

The longest period of time that a tube was left in place was 43 days. However, subglottic stenosis subsequently developed in this patient. The longest period of intubation without complications following extubation was 28 days, in an infant with tetanus. The smallest patient treated with prolonged intubation ( 4 days) weighed $1.5 \mathrm{~kg}$.

Therefore, prolonged intubation may provide an acceptable alternative to the use of a tracheotomy tube in the short-term management of many respiratory problems. Advantages of endotracheal intubation include the ease with which a tube can be simply and rapidly inserted and the prevention of complications associated with a tracheotomy such as interstitial emphysema, pneumothorax, haemorrhage, and frequent difficulty in decannulation.

In nearly all of the cases in this series, prolonged intubation was employed in patients requiring assisted or controlled ventilation. In our experience, patients on respirators, particularly infants and small children, can be more effectively ventilated using nasotracheal tubes with a relatively air-tight system than is possible with uncuffed tracheotomy tubes.

\section{Patients after Cardiovascular Surgery}

Half of the cases (51\%) were postoperative cardiac patients. In most of them, a nasotracheal tube was inserted prophylactically at the completion of the surgical procedure. Thus it was easy to provide assisted or controlled ventilation in the critical hours and days postoperatively. Without this technique, a number of patients would have required a tracheotomy or would have been compelled to expend their limited energy reserves to maintain adequate ventilation. With the work of breathing taken over, the energy expenditure by the patient is greatly reduced and the work load on the heart is correspondingly diminished. In addition, optimal blood gas tensions can be more effectively maintained.

\section{Patients with Status Asthmaticus}

Endotracheal intubation for 24 hours or longer was used in seven patients in status asthmaticus. In all of them, intubation was carried out only when it was apparent that they were not responding to the usual therapeutic measures. 
Treatment following intubation included: $(a)$ bronchial lavage with liberal amounts of saline; $(b)$ the use of either intermittent positive pressure or positivenegative pressure (in one of the patients a pressure of $70 \mathrm{~cm}$. of water was initially required to inflate the lungs); $(c)$ the administration of isoproterenol and epinephrine aerosols; $(d)$ the administration of steroids; $(e)$ the use of muscle relaxants (gallamine or d-tubocurare) in three of the cases; $(f)$ correction of metabolic acidosis.

All seven patients showed marked improvement within 24 hours. Airway obstruction following extubation occurred in three patients, suggesting a high incidence in this disease. Preventative measures are emphasized, including (a) careful selection of tube size, particularly in the presence of upper airway pathology; $(b)$ the use of steroids following extubation to minimize oedema of the tracheal mucosa; $(c)$ the use of sedatives and/or curarization to minimize movement of the tube in the trachea; $(d)$ effective humidification of inspired gases and adequate hydration of the patient; $(e)$ the use of plastic rather than rubber endotracheal tubes.

Finally, the successful use of prolonged intubation is largely dependent upon the availability of a well-trained nursing staff to care for the patients on a 24-hour basis, with experienced physicians immediately available at all times.

\section{SUMMARY}

The use of prolonged nasotracheal intubation in paediatric patients requiring assisted or controlled ventilation has been described. Particular emphasis has been placed on the method of management and possible complications of the technique. It is our opinion that prolonged nasotracheal intubation is a useful technique, particularly in the short-term management of many respiratory problems.

\section{RÉSUMÉ}

Actuellement, selon toute apparence, on peut laisser en place des tubes endotrachéaux, en toute sécurité, durant des périodes beaucoup plus longues que l'on acceptait antérieurement. Les auteurs ont employé cette technique à l'Hôpital des enfants malades (Hospital for Sick Children) de Toronto et ils font part de leur expérience sur un total de 156 malades intubés durant 24 heures et plus dont 74 survivants depuis longtemps. Ces malades n'ont fait l'objet d'aucun choix et l'on a employé cette technique chez eux sans tenir compte de leur pronostic. Parmi ceux qui sont morts, l'intubation prolongée n'a pas été un facteur important dans la cause du décès.

La surprise que cette technique nous a causée fut de réaliser combien facilement les malades pouvaient garder en place un tube endotrachéal. Si on explique à des malades plus âgés la nécessité de garder un tube dans les voies respiratoires, en ajoutant une légère sédation, il est étonnant comme tout cela s'endure facilement.

La période la plus longue durant laquelle on a laissé un tube endotrachéal en 
place a été de 43 jours. Toutefois, chez ce malade il s'est développé une sténose sans glottique. La période la plus longue durant laquelle on a laissé un tube en place sans qu'apparaissent de complications par la suite a été de 28 jours; il s'agissait d'un enfant souffrant de tétanos.

Le plus petit enfant qui a subi une intubation prolongée pesait 1.5 kilo et n'avait que 4 jours. Dans tous les cas de problèmes respiratoires à court terme, l'intubation prolongée peut être une alternative à la trachéotomie. L'avantage de l'intubation endotrachéale réside dans la facilité et la rapidité avec laquelle un tube peut être mis en place et la prévention des complications qui peuvent survenir à la suite de la trachéotomie: l'emphysème interstitiel, le pneumothorax, l'hémorragie et la difficulté d'enlever la canule.

Dans cette série, presque tous les malades qui ont eu une intubation prolongée réquéraient une ventilation assistée ou controlée. Les malades sous respirateurs, spécialement les poupons et les petits enfants, peuvent être ventilés plus efficacement en employant des tubes nasotrachéaux avec un système relativement étanche qu'on ne peut le faire avec des canules à trachéotomie sans ballonnet.

Le succès de l'usage de l'intubation prolongée réside en grande partie dans la présence d'une équipe d'infirmières bien préparées aux soins de ces malades, soins procurés 24 heures par jours, ainsi que de médecins d'expérience disponibles immédiatement en tout temps.

\section{REFERENCES}

1. ReEs, G. J. Personal communication.

2. McDonald, I. H. \& Stocks, J. G. Prolonged. Nasotracheal Intubation; A Review of its Development in a Paediatric Hospital. Brit. J. Anaesth. 37: 161 (1965).

3. Allen, T. H. \& Steven, I. M. Prolonged Endotracheal Intubation in Infants and Children. Brit. J. Anaesth. 37: 556 (1965).

4. Thomas, D. V., Fletcher, G;; Sunshine, P.; Schafer, I. A.; \& Klaus, M. H. Prolonged Respirator Use in Pulmonary Insufficiency of Newborn. J.A.M.A. 193: 183 (1965).

5. Reim, D. H. S. \& Tunstall, M. E. The Respiratory Distress Syndrome of the Newborn. Anaesthesia. 21: 72 (1966). 